Article

\title{
Carbon Nanotubes (CNTs) in Asphalt Binder: Homogeneous Dispersion and Performance Enhancement
}

\author{
Muhammad Faizan ul Haq ${ }^{1, * \mathbb{D}}$, Naveed Ahmad ${ }^{1}$, Muhammad Ali Nasir ${ }^{2}{ }^{(}$, Jamal ${ }^{3}$,

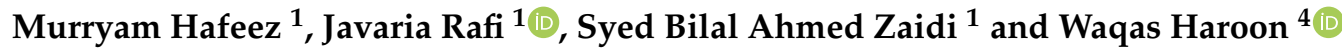 \\ 1 Department of Civil Engineering, University of Engineering and Technology Taxila, Taxila 47080, Pakistan; \\ n.ahmad@uettaxila.edu.pk (N.A.); murryamhafeez77@outlook.com (M.H.); javariarafi@outlook.com (J.R.); \\ bilal.zaidi@uettaxila.edu.pk (S.B.A.Z.) \\ 2 Department of Mechanical Engineering, University of Engineering and Technology Taxila, Taxila 47080, \\ Pakistan; ali.nasir@uettaxila.edu.pk \\ 3 Department of Civil Engineering, Royal Melbourne Institute of Technology University, Victoria 3053, \\ Australia; jamal.naasir209@gmail.com \\ 4 Department of Civil Engineering, International Islamic University Islamabad, Islamabad 44000, Pakistan; \\ waqas.haroon@iiu.edu.pk \\ * Correspondence: Faizan.ul@students.uettaxila.edu.pk; Tel.: +9-231-6188-1117
}

Received: 9 November 2018; Accepted: 10 December 2018; Published: 17 December 2018

\begin{abstract}
Conventional binders cannot meet the current performance requirements of asphaltic pavements due to increase in traffic volumes and loads. Nanomaterials, due to their exceptional mechanical properties, are gaining popularity as bitumen modifiers to enhance the performance properties of the asphaltic concrete. Carbon Nanotubes (CNTs) are one of the most widely used nanomaterials because of their strength properties, light weight, small size, and large surface area. CNT addition results in improved substrate characteristics as compared to other modifiers. Due to high length to diameter ratio, dispersion of CNTs in bitumen is a complex phenomenon. In this study, dispersion of CNTs in bitumen was carried out using both dry and wet mixing techniques, the latter was selected on the basis of homogeneity of the resultant asphalt mixture. Scanning Electron Microscopy (SEM) was used to check the dispersion of CNTs in binder while Fourier Transform Infrared Spectroscopy (FTIR) was carried out to ensure the removal of solvent used for wet mixing. Conventional bitumen tests (penetration, softening point, and ductility), dynamic shear rheometer tests, rolling bottle tests, and bitumen bond strength tests were employed to check the improvement in the rheological and adhesion properties of bitumen while wheel tracker test was used to check the improvement in resistance against permanent deformation of asphalt mixtures after addition of CNTs. Results show that CNTs improved the higher temperature performance and permanent deformation resistance in both binder and mixtures. Improvement in bitumen-aggregate adhesion properties and moisture resistance was also observed.
\end{abstract}

Keywords: Carbon Nanotubes (CNTs); wet mixing; bitumen; homogeneous dispersion; rutting; adhesion

\section{Introduction}

An efficient transport network plays a key role in the economic development of a country and, therefore, the kilometrage of paved roads existing in a country is often used as an index to assess the extent of its development [1]. Asphalt mixtures have been widely used for construction of road for a long time now and bitumen is its main constituent [2]. Due to a rapid increase in the traffic loading and 
volume, pavements in Pakistan fail prematurely and the revival of their serviceability normally requires a lot of resources and finance. Pavements constructed utilizing conventional materials (especially virgin bitumen with softening points far less than the temperatures to which the pavements are exposed) fail many times within the design life, putting a lot of burden on the annual maintenance budget and ultimately increasing the life cycle cost of the pavement. If the bitumen were made to last/survive longer, pavement failures could be delayed, which would minimize the life cycle cost of the pavements. Regular wear and tear are expected but total failure before the end of the design life, as often happens in Pakistan, is not desirable. It not only increases the maintenance costs but also adds nuisances for the road users in terms of delays, accidents, and vehicle operating costs. This study aimed to address this issue [3]. Local traditional pavement materials in Pakistan are falling short in meeting the practical demands for present and future highway pavement construction. Thus, higher quality, more sustainable, more reliable and more environment friendly pavement materials are urgently demanded [4].

Civil engineering materials modification through addition of polymers and other additives such as fly ash and lime has often been utilized [5]. The use of Polymer Modified Asphalts (PMAs) allows the construction of safer roads and important reduction in maintenance costs [6-8]. Different modifiers such as crumb rubber and polymers are also used to improve the mechanical properties of conventional asphalts. Although modifiers improve the performance of asphalt, increases in traffic loads and volumes, harsh weather conditions, and the ever-increasing asphalt cost call for more research in this area [9]. Pavement engineers continuously look for innovative additives/modifiers to enhance the performance properties of road materials. Nanotechnology has recently gained popularity in the scientific world. Due to remarkable achievements of nanotechnology in other fields of engineering, researchers have started looking into its utilization in the field of civil engineering. Nanotechnology is often used for the modification and enhancement in properties of cement concrete [10,11]. The effect of nanomaterials on the properties of asphalt concrete is an emerging field that must be explored.

Nanotechnology and its influence on improving the characteristics and performance of asphalt pavements has lately received much attention from researchers [12]. Two specific types of nanomaterials, namely nano-metal oxides and nano-inorganic materials, have been widely investigated. Nano-metal oxides such as nano- $\mathrm{TiO}_{2}$, nano- $\mathrm{SiO}_{2}$, and nano- $\mathrm{ZnO}$ can improve the rutting resistance of bitumen, but have little effect on its low temperature cracking resistance [13-15]. Nano-inorganic materials including nano-clay and Carbon Nanotubes (CNTs) hold the potential to redefine the field of traditional materials in terms of both performance and potential applications [16-18]. CNTs are among the most widely used nanomaterials because of their strength properties, light weight, small size, and large surface area. CNTs are basically long hollow cylinders of graphene sheet, which have a diameter starting from approximately $1 \mathrm{~nm}$. They were first discovered by Sumio Iijima in 1991 [19]. CNTs are characterized by superior mechanical properties when compared with other construction materials [20]. Depending on the radius of the tube, the Young's modulus of a CNT can be as high as $1000 \mathrm{GPa}$ [21] and the tensile strength can reach $150 \mathrm{GPa}$ [22]. Because of their small size and large surface area, $\mathrm{CNT}$ addition results in improved substrate characteristics as compared to other modifiers. There are two different types of CNTs, i.e., single (called single-walled CNTs) and coaxial tubes (called multiple-walled CNTs) [6]. Multi-walled CNTs (MWCNTs) are less expensive and easier to produce but exhibit lower strength and stiffness than single-wall CNTs [23]. The most common techniques used to produce CNTs are arc discharge, chemical vapor deposition and laser ablation.

Different researchers use different dosages of CNTs as a modifier to enhance the properties of asphalt binder. Gong et al. (2017) investigated the effect of CNTs on performance, chemical and structural properties of asphalt binder [24]. Amin et al. (2016) used MWCNTs as an additive in bitumen and concluded that the modification improved both high and low temperature performance of bitumen [9]. Galooyak et al. (2015) added MWCNTs in asphalt binder and examined the effects on conventional and rheological properties and concluded that CNTs improved the rheological as well as conventional properties of bitumen [25]. Previous studies have also observed that CNTs 
enhance the resistance of asphalt against ageing, which results in the increase in the pavement life $[9,26]$. The biggest challenge in developing CNTs reinforced material is the dispersion of CNTs in base binder. To homogeneously disperse the CNTs in bitumen, long chains of CNTs produced by synthesis and agglomerates of CNTs produced by intermolecular van der Walls forces must be broken [27]. Inappropriate dispersion of CNTs may affect the mechanical properties of modified binder. CNTs are dispersed in bitumen using either dry or wet mixing technique. Most previous work has been carried out using dry mixing, while limited work has been done using the wet mixing technique. Faramarzi et al. (2015) used both wet and dry mixing techniques and concluded that wet mixing technique has better ability to homogeneously disperse CNTs as compared to the dry method. They used kerosene as a solvent [28]. The drawback found by Faramazi et al. was that kerosene did not fully evaporate from the bitumen after mixing, which may influence the resulting binder properties. Ziari et al. (2012) compared different mixers and concluded that, with high shear mixer and ultrasonic mixer, homogeneous dispersion of CNTs can be achieved [29]. In the literature, although wet mixing is a better dispersion technique, the selection of appropriate solvent and its complete evaporation after achieving a homogeneous dispersion matters greatly. Therefore, a thorough study from this perspective was carried out in this study.

This study consisted of two parts. The first part of this manuscript focuses on the dispersion of CNTs in asphalt binder, while the second part studies the effect of CNTs on the performance properties of resulting asphalt binder. Dispersion of CNTs in bitumen is a complex phenomenon [24,28,29]. Although different researchers use CNTs in asphalt binder to enhance the properties of asphalt binder, to authors' best knowledge, no comprehensive study is available on the dispersion of CNTs in bitumen. In this research, a detailed methodology was developed for the homogeneous dispersion of CNTs in bitumen. In addition, previous work mostly studies the effect of CNTs on the rheological properties of bitumen, but the effect of CNT addition on bitumen-aggregate adhesion and moisture sensitivity needs to be explored.

\section{Experimental Work}

\subsection{Materials}

A 60/70 penetration grade bitumen supplied by Attock Refineries Limited (ARL), Pakistan was used as a base binder. MWCNTs were imported from US-Nano, USA. Basic properties of base binder and MWCNTs are presented in Tables 1 and 2, respectively.

Table 1. Properties of Base Binder.

\begin{tabular}{ccc}
\hline Test & Value & Standard \\
\hline Penetration Value $\left(0.1 \mathrm{~mm}, 25^{\circ} \mathrm{C}\right)$ & 64 & ASTM D5 \\
Softening Point $\left({ }^{\circ} \mathrm{C}\right)$ & 49 & ASTM D36 \\
Ductility mm $\left(25^{\circ} \mathrm{C}\right)$ & 102 & ASTM D113 \\
\hline
\end{tabular}

Table 2. Properties of Multiwall Carbon Nanotubes used for Bitumen Modification.

\begin{tabular}{ccccccc}
\hline $\begin{array}{c}\text { Inner } \\
\text { Diameter }\end{array}$ & $\begin{array}{c}\text { Outer } \\
\text { Diameter }\end{array}$ & $\begin{array}{c}\text { Average } \\
\text { Length }\end{array}$ & Purity & Density & $\begin{array}{c}\text { Specific } \\
\text { Surface Area }\end{array}$ & Manufacturing Method \\
\hline $30-50 \mathrm{~nm}$ & $5-12 \mathrm{~nm}$ & $0.5-2 \mu \mathrm{m}$ & $>90 \%$ & $2.1 \mathrm{~g} / \mathrm{cm}^{3}$ & $60 \mathrm{~m}^{2} / \mathrm{g}$ & Chemical Vapor Deposition \\
\hline
\end{tabular}

Scanning Electron Microscopy (SEM) images of CNTs are presented in Figure 1 showing the morphology of the selected CNTs at different magnifications. 

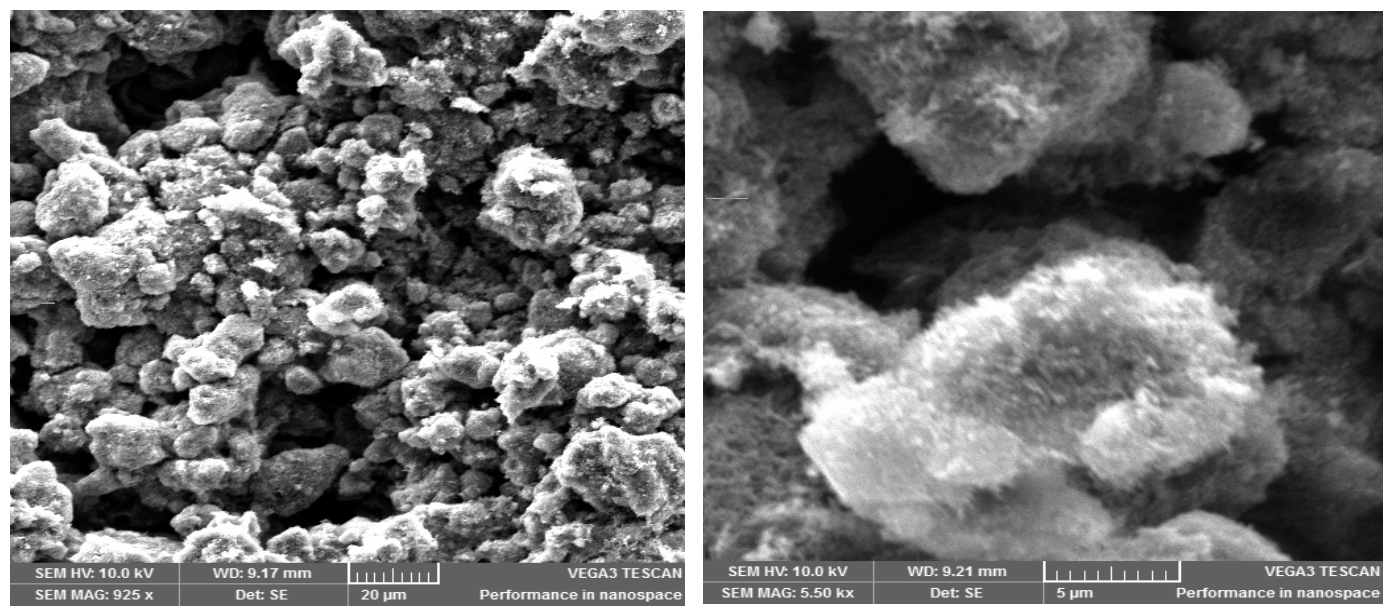

Figure 1. SEM images of CNTs.

Aggregates were procured from Margalla quarries, and was basically limestone [30]. The gradation curve for the aggregate material used in this study is presented in Figure 2. The general specifications of the National Highway Authority (NHA) were followed for the selection of material. NHA (a government owned organization for the development of highways) class B gradation for asphalt concrete wearing coarse was selected for the study. Midpoint gradation was used. Mechanical properties of the utilized aggregates are given in Table 3.

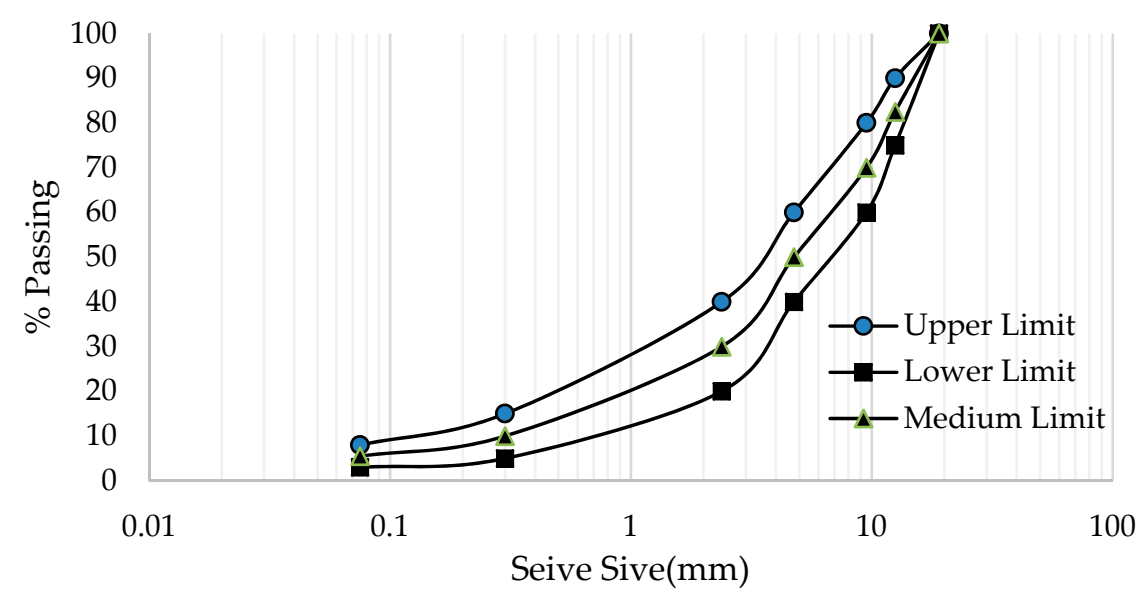

Figure 2. Gradation Curve of aggregates used for asphalt mixtures.

Table 3. Material Properties of Margalla aggregate used in this research [31].

\begin{tabular}{cccc}
\hline Property & Standard & Value & Limit \\
\hline Los Angeles Abrasion (Coarse) & ASTM C 131 & 15 & $\leq 15 \%$ \\
Soundness (Course) & ASTM C 88 & 7.1 & $\leq 8 \%$ \\
Soundness (Fine) & ASTM C 88 & 4.7 & $\leq 8 \%$ \\
Water Absorption (Coarse) & ASTM C 127 & 1.02 & $\leq 2 \%$ \\
Uncompacted Voids (Coarse) & ASTM C 1252 & 37.5 & $\geq 45 \%$ \\
Flakiness (Coarse) & BS 812.108 & 5 & $\leq 15 \%$ \\
Elongation (Coarse) & BS 812.109 & 11 & $\leq 15 \%$ \\
Fractured Particles (Coarse) & ASTM D 5821 & 100 & $\geq 90 \%$ \\
Sand Equivalent (Coarse) & ASTM D 2419 & 75 & $\geq 50 \%$ \\
\hline
\end{tabular}




\subsection{Sample Preparation}

It can be observed from the Scanning Electron Microscopy (SEM) images of CNTs given in the Figure 1 that these tubes are intertwined with each other. This means that higher efforts are required to properly disperse CNTs in bitumen. The most difficult process in bitumen modification with CNTs is its homogeneous dispersion because of their aggregation, which leads to unsatisfactory results. There are two ways to disperse CNTs in bitumen: (i) dry mixing; and (ii) wet mixing. In dry mixing technique, CNTs are directly added into bitumen and dispersed with mixers at high frequencies. In wet mixing technique, CNTs are first dissolved in a solvent. This solution is then dispersed in bitumen with mixers. Different nanomaterials require different mixing conditions for their dispersion in bitumen. For some nanomaterials, dry mixing and mechanical stirrer is sufficient to disperse them in bitumen, while some require high shear mixing and wet mixing for homogeneous dispersion. Thus, a thorough study was required on uniform dispersion of CNTs in asphalt binder.

In this study, sample preparation involved three major steps:

1. Mixer selection

2. Solvent selection

3. Technique (dry/wet) selection

\section{Mixer Selection}

Mechanical stirrer and high shear mixer (locally fabricated) were used for the dispersion of CNTs in bitumen. Researchers have utilized different mixing techniques for dispersion of nanomaterials in bitumen. The most commonly selected instruments are mechanical stirrer and high shear mixer. Mechanical stirrer uses simple propeller/fan blade configuration for mixing, while high shear mixer generates a vortex type movement within the material to ensure fast and aggressive mixing [29]. This study evaluated both types of mixers. One mixer (mechanical stirrer and high shear mixer) was selected based on dispersion of CNTs in asphalt binder. In many previous studies, mixing rate of around $1500 \mathrm{rpm}$ with mechanical stirrer has been used for the dispersion of CNTs in bitumen [25,28,32] while a mixing speed of around $3000 \mathrm{rpm}$ is generally selected for high shear mixer [29,33]. These mixing rates were selected for this study as well. CNTs content, mixing temperature, and mixing time were kept constant for both mixers. One percent by mass of bitumen was taken as CNT content, while mixing temperature and mixing time were $158 \pm 5^{\circ} \mathrm{C}$ and $45 \mathrm{~min}$, respectively. SEM images were used to compare the dispersion of CNTs in bitumen for both mixers. Microscopy (SEM) specimen was examined point by point directly in a moving electron beam. Electrons reflected by the specimen were used to form a magnified, three-dimensional image on a television screen [34]. Bitumen is a petroleum product and contains volatile compounds, which is why, when subjected to focused electron beam during SEM test, the volatile compounds of bitumen evaporate due to high temperature, which not only contaminates the SEM chamber but also makes the scanning process difficult. To avoid this, sputtering of SEM samples was carried out. During the sputtering process, the bitumen sample was placed in a vacuumed reservoir and coated with thin layers of gold palladium. SEM analysis provided in Section 2.4.1 shows that mechanical stirrer was unable to break the agglomerates of the CNTs, while high shear mixer was able to disperse CNTs more uniformly. Hence, high-shear mixer was selected to disperse CNTs uniformly into the asphalt binder for sample preparation.

\section{Solvent Selection for Wet Mixing}

The main problem in wet mixing is the selection of solvent that can fully evaporate leaving behind the dispersed CNTs. If solvent remains in bitumen, then it can affect its properties and the real effect of CNTs cannot be judged. Three solvents, i.e., methanol, acetone and toluene, were tested for time of evaporation. Each solvent was separately mixed in bitumen using high shear mixer for 5 min at $3000 \mathrm{rpm}$. To evaporate the solvent, these mixes were kept in an oven at $158 \pm 5{ }^{\circ} \mathrm{C}$ and were continually (manually) stirred until a constant mass was achieved. The time taken by each solvent to 
fully evaporate from the modified bitumen was also noted. Methanol was selected as the solvent due to the shorter time taken for its removal from the bitumen.

\section{Technique (Dry/Wet) Selection}

Samples were prepared using both wet and dry mixing techniques. Hot storage test was used to evaluate the high temperature storage stability of modified bitumen. An aluminum tube $(25 \mathrm{~mm}$ in diameter and $140 \mathrm{~mm}$ in height) was filled with about $50 \mathrm{~g}$ of hot CNT-modified bitumen, and then stored vertically in an oven at $163{ }^{\circ} \mathrm{C}$ for $48 \mathrm{~h}$. It was then taken out and cooled in a refrigerator at $-7^{\circ} \mathrm{C}$ for $4 \mathrm{~h}$. Finally, the tube was cut into three equal sections. The difference of softening point value between top and bottom section of tube is known as Separation Index (SI). If SI is less than $2.2^{\circ} \mathrm{C}$, the sample is regarded as storage stable according to ASTM D5892. With dry mixing, maximum SI was about $2.5^{\circ} \mathrm{C}$, while, in wet mixing, it was about $1.3^{\circ} \mathrm{C}$, thus the sample prepared using wet mixing was storage stable. Wet mixing technique was selected for this study. Thus, the samples were prepared using wet mixing technique with methanol as a solvent using high shear mixer.

\subsection{CNTs Modified Asphalt Binder Preparation}

Four different percentages of CNTs $(0.5 \%, 1 \%, 1.5 \%$ and $3 \%)$ by mass of the asphalt binder were used in this study. CNTs were added into the methanol. The Solution was first stirred with the help of magnetic stirrer at $550 \mathrm{rpm}$ for $3 \mathrm{~h}$ to break the CNT agglomerates. Then, the solution was kept in a sonication bath for $2 \mathrm{~h}$ to disperse the CNTs in solvent. This is important for the proper dispersion of CNTs in the solvent and its stability at room temperature, as shown in Figure 3. During this process, the solvent was covered with aluminum foil so that the methanol did not evaporate during sonication and stirring. A homogeneously mixed black color solution was obtained having high stability at room temperature, as shown in Figure 3.

After homogeneous dispersion of CNTs in methanol, the solution was mixed in bitumen with the help of high shear mixer at $3000 \mathrm{rpm}$ for $45 \mathrm{~min}$ to ensure homogeneous mixing as well as to complete evaporation of methanol. Temperature was kept at $158 \pm 5{ }^{\circ} \mathrm{C}$ during mixing with the help of oil bath.

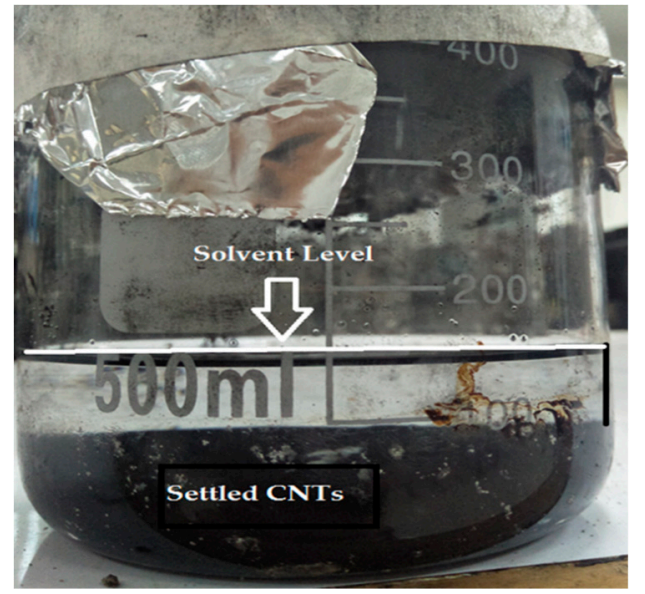

(a)

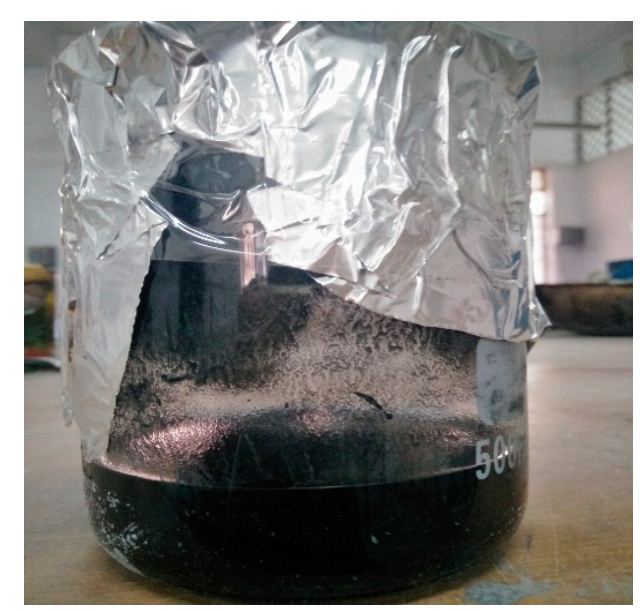

(b)

Figure 3. (a) CNTs in solvent before sonication; and (b) CNTs in solvent after sonication and stirring.

\subsection{Investigation into Homogeneous Dispersion}

\subsubsection{SEM Analysis}

SEM was carried out to check the homogeneous dispersion of CNTs in bitumen. Mixing using high shear technique resulted in better dispersion of CNTs in the bitumen. Figure 4 shows an SEM image of CNT-modified asphalt binder prepared using mechanical stirrer, while Figure 5a,b shows the SEM images of CNT-modified asphalt binder prepared using high shear mixer. Figure 4 clearly shows 
CNT agglomerates with mechanical stirrer, while Figure 5a shows evenly distributed CNTs, even at a higher magnification.

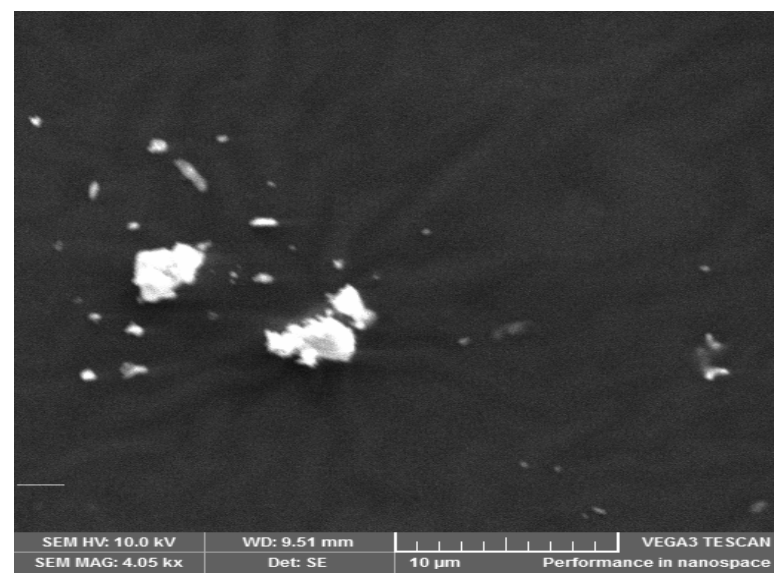

Figure 4. CNTs dispersion in bitumen using mechanical stirrer.

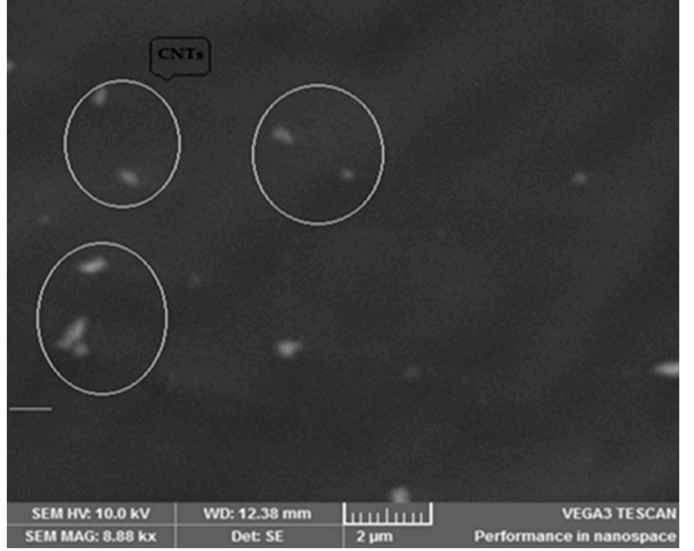

(a)

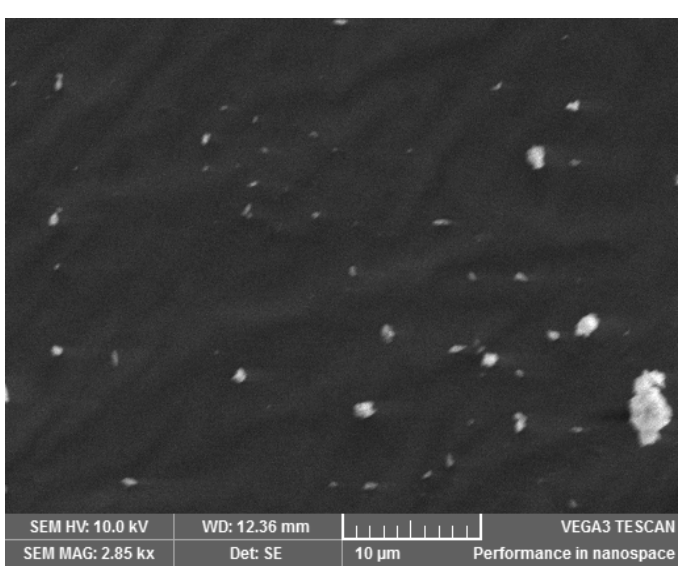

(b)

Figure 5. CNTs dispersion in bitumen using high shear mixer at different magnifications.

\subsubsection{FTIR Analysis}

FTIR was used to check for the complete removal of solvent from the modified binder. The test was performed according to ASTM E1552. For FTIR (6700 Nicolet, Thermo Science, Waltham, MA, USA) spectrometers was used to get the asphalt spectra in the range of $400-4000 \mathrm{~cm}^{-1}$ wavenumber. It can be seen from the FTIR spectra shown in Figure 6 that no new chemical functional groups were formed with the addition of MWCNTs, and all different concentrations of MWCNTs showed a similar trend. Thus, the MWCNTs did not chemically react with bitumen. Methanol $\left(\mathrm{CH}_{3} \mathrm{OH}\right)$ was used as a solvent in wet mixing technique to disperse the CNTs in bitumen. In methanol, functional group -OH is present and in FTIR spectrum the peak of $-\mathrm{OH}$ alcohol group appears at $3200-3700 \mathrm{~cm}^{-1}$ wavenumber spectra. In Figure 6, it is clear that, in the FTIR spectra, no peak appears at that range of -OH functional group, which means the solvent was completely evaporated and no effect of methanol was left. Any change in the properties of asphalt can only be attributed to the addition of CNTs in asphalt binder. 


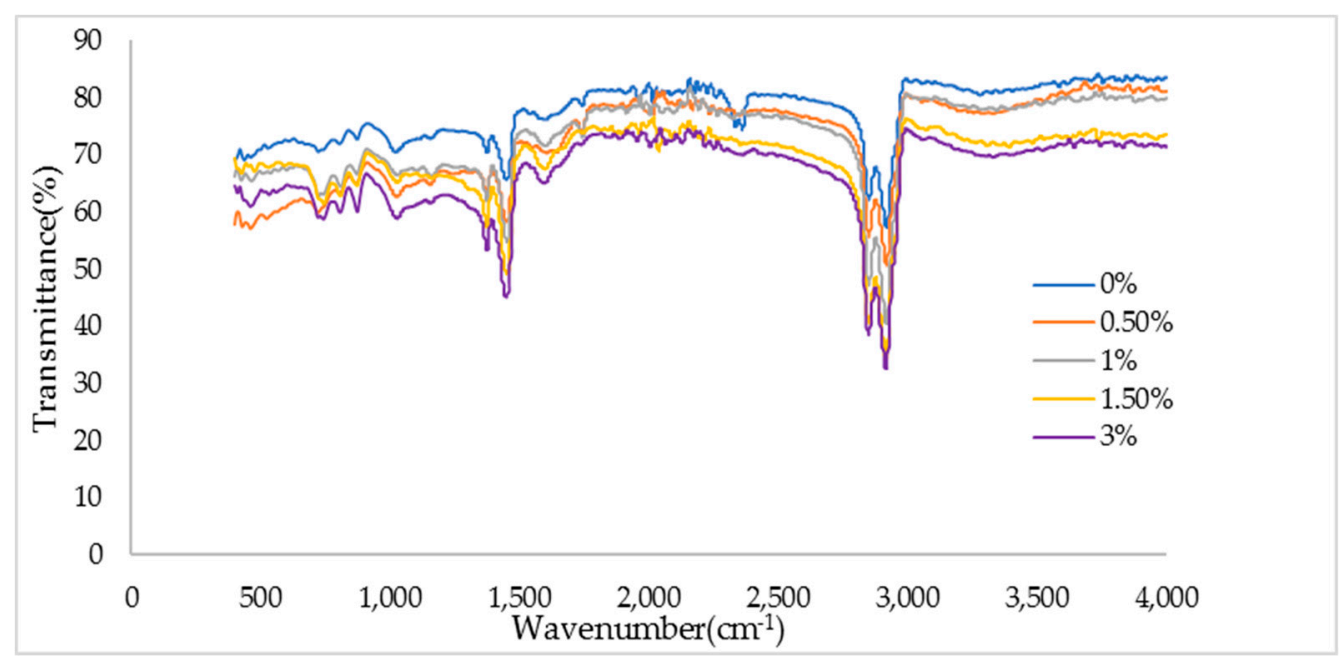

Figure 6. FTIR of unmodified and CNT-modified bitumen.

\subsubsection{Storage Stability Test}

Storage stability test also ensured the homogeneous dispersion of CNTs in the binder. The difference in Softening Point (SP) of the represented sample taken from the top and bottom of the storage test aluminum tube was within the permissible limit $\left(2.2^{\circ} \mathrm{C}\right)$ for wet mixing technique. The results are shown in Table 4.

Table 4. Storage stability test data for CNT-modified and unmodified binder.

\begin{tabular}{cccccc}
\hline CNTs Dosage & $\mathbf{0 \%}$ & $\mathbf{0 . 5 \%}$ & $\mathbf{1 \%}$ & $\mathbf{1 . 5 \%}$ & $\mathbf{3 \%}$ \\
\hline SP of Top Portion $\left({ }^{\circ} \mathrm{C}\right)$ & 48.9 & 50.7 & 55.4 & 57 & 57.8 \\
SP of Bottom Portion $\left({ }^{\circ} \mathbf{C}\right)$ & 49.1 & 51.7 & 56.7 & 58.5 & 59.7 \\
Difference $\left({ }^{\circ} \mathbf{C}\right)$ & 0.2 & 1 & 1.3 & 1.5 & 1.9 \\
\hline
\end{tabular}

\subsection{Engineering Properties Analysis}

\subsubsection{Conventional Binder Tests}

Penetration, softening point, and ductility tests were performed in accordance with ASTM D5, ASTM D36 and ASTM D113, respectively. The tests were performed to study the change in these properties before and after the CNT addition in asphalt binder.

\subsubsection{Dynamic Mechanical Analysis (DMA)}

For dynamic mechanical analysis, Dynamic Shear Rheometer (DSR) model MCR101 manufactured by Anton Paar (Gras, Austria) was used and the test was performed according to AASHTO T 315. DSR Plates of $25 \mathrm{~mm}$ dimeter with $1 \mathrm{~mm}$ gap were used to test the samples at temperatures higher than $46^{\circ} \mathrm{C}$ while $8 \mathrm{~mm}$ diameter plates with the gap of $2 \mathrm{~mm}$ were used for testing the samples at temperatures less than $46^{\circ} \mathrm{C}$. High temperature performance grading (PG) and frequency sweep tests were conducted. In frequency sweep, test strain was kept constant as per superpave criteria ( $10 \%$ for unmodified sample and $2 \%$ for modified sample) and frequency ranged $10-0.1 \mathrm{~Hz}$ at required temperatures.

\subsubsection{Bitumen Bond Strength Test}

Bitumen bond strength test was performed to check the adhesion of bitumen with aggregate after both dry and moist conditioning. Pneumatic Adhesion Tensile Tester Instrument (PATTI) manufactured by SEMicro (Derwood, MD, USA) was used to perform this test. Test was performed according to 
ASTM D4541. Geometry of the stub used for experiment is shown in Figure 7. BBS test was used to determine the bonding properties between aggregate and bitumen. Apparatus consists of metallic pull-off stub, reaction plate, pressure hose, piston, and a portable pneumatic adhesion tester. During the testing, pull-off force thorough air pressure was used to separate metallic stub from aggregate surface. Failure occurs when applied stresses are more than adhesive strength or cohesive strength.

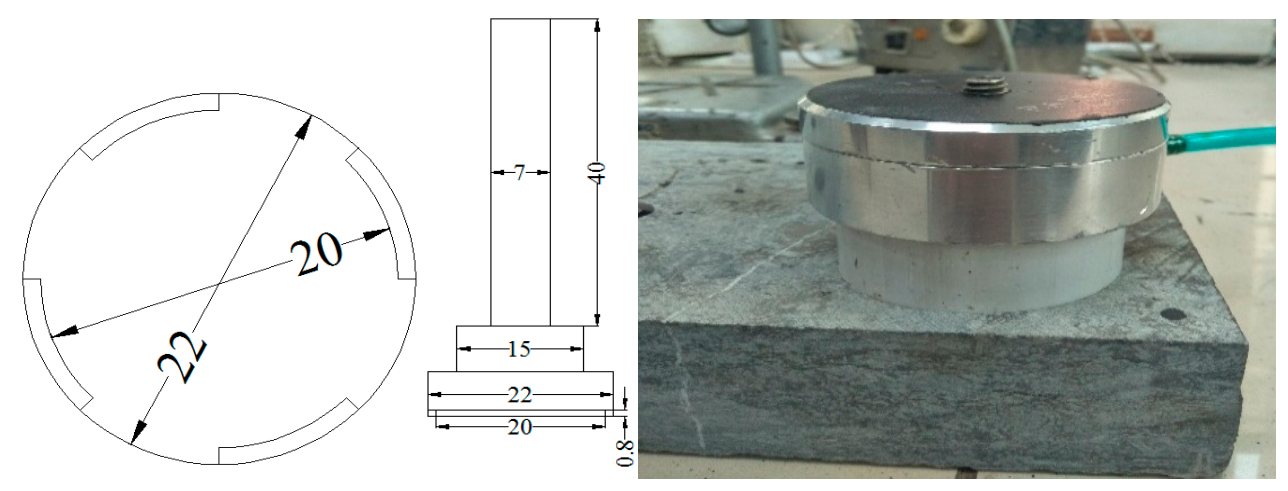

Figure 7. Dimensions of stub (mm) used in BBS test and piston setup.

Bitumen samples, limestone aggregate plates and pullout stubs were heated to $150{ }^{\circ} \mathrm{C}$ for a minimum of $30 \mathrm{~min}$ to remove absorbed water on the aggregate surface and to provide a better bond between the asphalt binder and the aggregate surface. The aggregate plates were brought to an application temperature of $60^{\circ} \mathrm{C}$, whereas the application temperature for the pullout stubs was $60{ }^{\circ} \mathrm{C}$. After a sufficient heat-up time, the molten asphalt samples were carefully poured in $8 \mathrm{~mm}$ diameter DSR silicon molds that were then left for $30 \mathrm{~min}$ to reach room temperature. Then, these bitumen samples were placed on the heated stubs and the stubs were firmly pressed vertically on aggregate plates until each stub was in contact with the aggregate surface. Excess bitumen was removed with cutter from all the prepared samples. For dry conditioning, prepared samples were kept at room temperature for $24 \mathrm{~h}$ before the test. In moist conditioning, samples were kept in deionized water at $25^{\circ} \mathrm{C}$ for $24 \mathrm{~h}$ before testing.

\subsubsection{Moisture Susceptibility Analysis}

Rolling bottle test was performed to measure the moisture susceptibility of asphalt. The test was performed according to BS EN 12697-11. First, $170 \mathrm{~g}$ of aggregate passing through an $8 \mathrm{~mm}$ sieve and retained on a $6.3 \mathrm{~mm}$ sieve were taken. Then, $8 \mathrm{~g}$ modified and unmodified binder samples were mixed with aggregate until all aggregate was fully coated with the bitumen. Then, these coated aggerate particles were placed in bottle and the bottles were filled with deionized water. Bottles were placed in the rolling machine and rotated at $60 \mathrm{rpm}$. Coating percentage of each sample was checked after 24 , 48 and $72 \mathrm{~h}$.

\subsubsection{Permanent Deformation Analysis}

Wheel tracker test was performed to determine the rutting of the asphalt mixtures under loading cycles. Test was performed according to BS EN 12697-22. Due to shortage of time and less quantity of materials, three slabs were prepared with $0 \%, 1 \%$ and $3 \%$ CNT content and the gradation used was NHA Class B. First, Marshall method of mix design was carried out to determine the optimum binder content of all three samples. Marshall method of mix design was performed as per ASTM D1559 using hammer weight to 4.5 lbs., hammer drop height of 18 inches and application of 75 blows on each side (for heavy traffic) of the specimen. OBC for unmodified sample was $4.38 \%$ while for $1 \%$ and $3 \%$ CNT-modified samples it was $4.42 \%$ and $4.47 \%$, respectively. Researchers have experienced both increases and decreases in the optimum binder content requirements when utilizing 
nanomaterials $[35,36]$. In this study, an increase in optimum binder content was experienced with the increase in CNT dosage. The same trend in $\mathrm{OBC}$ by adding nanomaterial was observed by Chelovian and Shafabakhsh [37]. This increase in OBC could be attributed to large surface area of CNTs used in this study. This could also be due to the increase in viscosity of the asphalt binder with the addition of addition of the nanomaterial which made binder stiff. A higher viscosity leads to a thicker binder film of the modified bitumen in the mix, thus increasing the binder volume in the mix [38,39].

Mixing of asphalt was done at $158 \pm 5{ }^{\circ} \mathrm{C}$ and compaction of asphalt was done at $145 \pm 5{ }^{\circ} \mathrm{C}$. A $300 \mathrm{~mm} \times 300 \mathrm{~mm} \times 50 \mathrm{~mm}$ slab was prepared and compacted with the help of cooper roller compacter in four different phases with $2.5,3.5,4$ and 4.5 bar pressure to maintain $5.5 \pm 0.5 \%$ air voids. The number of passes kept for the specimen was 10,000 and load applied during the test was $700 \pm 20 \mathrm{~N}$, while $40^{\circ} \mathrm{C}$ temperature was kept constant during test.

All the above-mentioned tests were performed at Taxila Institute of Transportation Engineering, University of Engineering and Technology Taxila, Pakistan.

\section{Results and Discussions}

\subsection{Conventional Asphalt Binder Properties}

Figure 8 shows the effect of MWCNTs on the penetration and softening point value of modified and unmodified bitumen. Penetration value reflects the stiffness and hardening of asphalt binder at moderate temperature. Lower penetration value indicates that binder has become stiff. In Figure 8 it can be seen that, by increasing CNTs in bitumen, the penetration value decreased, which is indicative of a decrease in fluency and increase in the stiffness of bitumen. When $0.5 \%$ (by mass of bitumen) CNTs was added, penetration significantly decreased by $11 \%$. By increasing the CNT dosage to $1.5 \%$ and $3 \%, 25 \%$ and $28 \%$ decreases in penetration value were observed, respectively. Increasing the CNT dosage beyond $1 \%$ did not have a significant effect on the penetration value.

The softening point test is commonly used as a standard test for describing an approximate limit between viscous and viscoelastic bitumen behavior, and it reflects the deformation resistance of bitumen at high temperature. A dosage of 1.5\% CNTs (by mass of bitumen) increased the softening point by about $7{ }^{\circ} \mathrm{C}$ as compared to base binder. When about $3 \%$ by mass of CNTs was added, it resulted in an increase in softening point of bitumen of about $8.4^{\circ} \mathrm{C}$. This increase in softening point and decrease in penetration value may be attributed to the large surface energy, high Young's modulus and presence of interaction forces between the CNTs, which make binder stiff $[40,41]$.

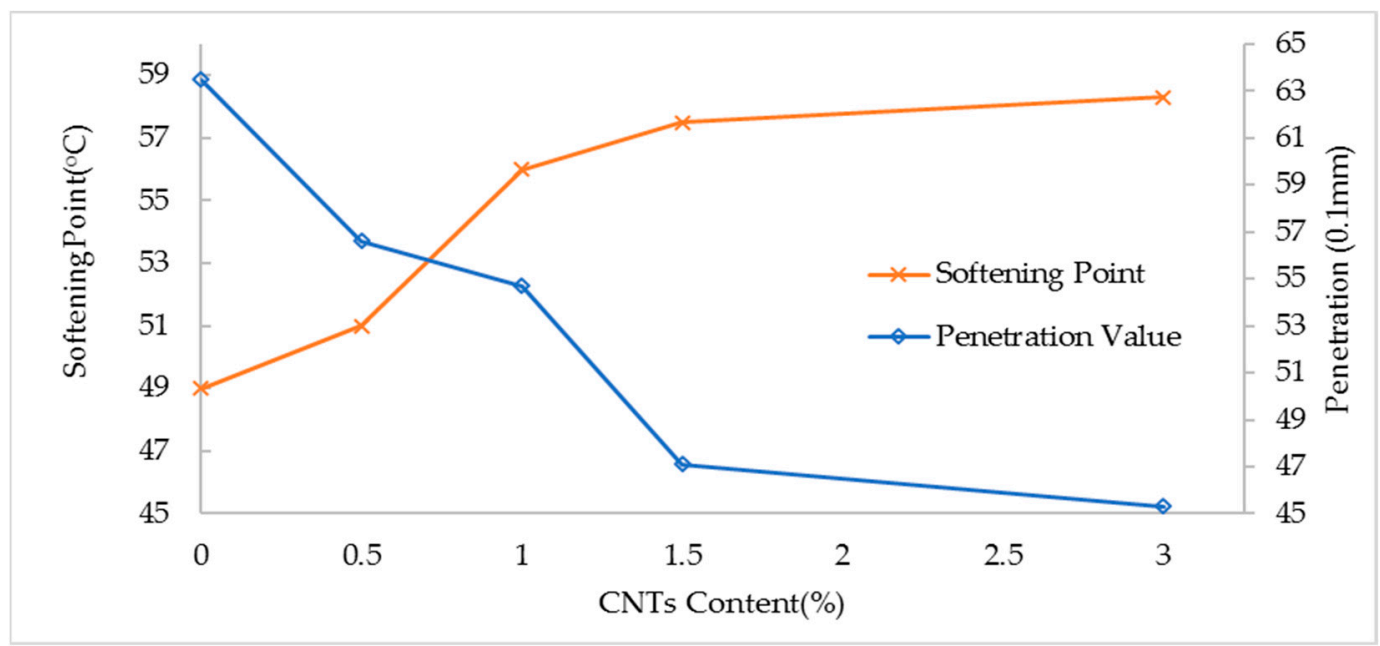

Figure 8. Effect on penetration value and softening point value with addition of CNTs. 
PI was used to study the effect of the addition of CNTs in the asphalt binder on its temperature susceptibility. The temperature susceptibility evaluation is described below, as illustrated by Ahinola et al. [42], using following equations.

$$
P I=\frac{20-500 A}{1+50 A} \text { where } A=\frac{\log (800)-\log (\text { Pen at } T)}{S P-25}
$$

where $T$ is the temperature at which the penetration test is performed $\left(25^{\circ} \mathrm{C}\right), P e n$ at $T$ is the penetration at the required temperature $T(0.1 \mathrm{~mm}), S P$ is the softening point of asphalt $\left({ }^{\circ} \mathrm{C}\right)$, and $P e n$ at $S P$ is the penetration at the softening point and assumed as $800(0.1 \mathrm{~mm})$ [43].

Higher value of $P I$ indicates lower temperature susceptibility. In addition, it is known that most asphalt binders have PI values between -2 and +2 . Binders are considered as highly temperature susceptible if their PI values go below -2 and they will be more brittle at lower temperatures and experience transverse cracking in cold weather regions [44].

The PI results for all the used CNTs percentages, as shown in Table 5 and Figure 9, are within the normal PI ranges (from -2 to +2 ). With the addition of CNTs, the PI value of bitumen increased, which means the bitumen temperature susceptibility decreased.

Table 5. Penetration Index for modified and unmodified bitumen.

\begin{tabular}{cccccc}
\hline Sample & $\mathbf{0 \%}$ CNTs & $\mathbf{0 . 5 \%}$ CNTs & $\mathbf{1 \%}$ CNTs & $\mathbf{1 . 5 \%}$ CNTs & 3\% CNTs \\
\hline PI & -0.7692 & -0.66 & 0.0187 & 0.060 & 0.065 \\
A & 0.04584 & 0.0442 & 0.03758 & 0.0378 & 0.0374 \\
\hline
\end{tabular}

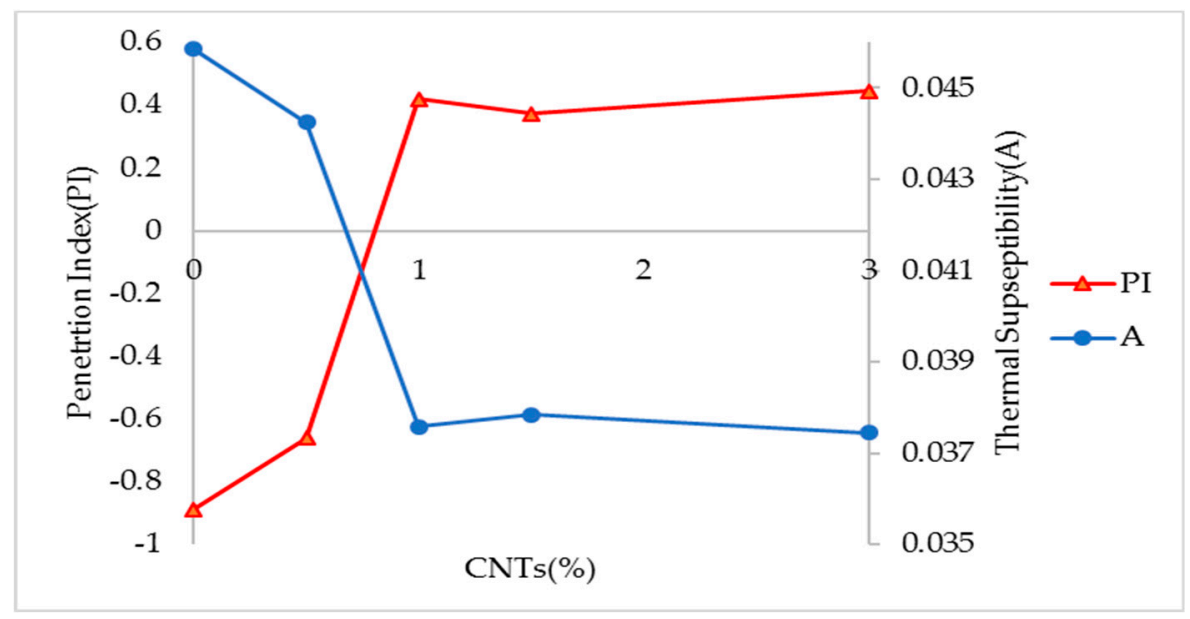

Figure 9. Effect on Penetration Index and Thermal Susceptibility with addition of CNTs.

Figure 10 shows that decrease in ductility was observed with addition of CNTs. A 21\% decrease in ductility value was observed when CNT content of up to $1.5 \%$ was added in bitumen. With $3 \%$ addition of CNTs, ductility value reduced by $26 \%$ as compared to neat binder. This reduction in ductility value was due to increase in stiffness of bitumen with the addition of CNTs, which accelerated the bitumen fracture process when subjected to tensile stress [11]. 


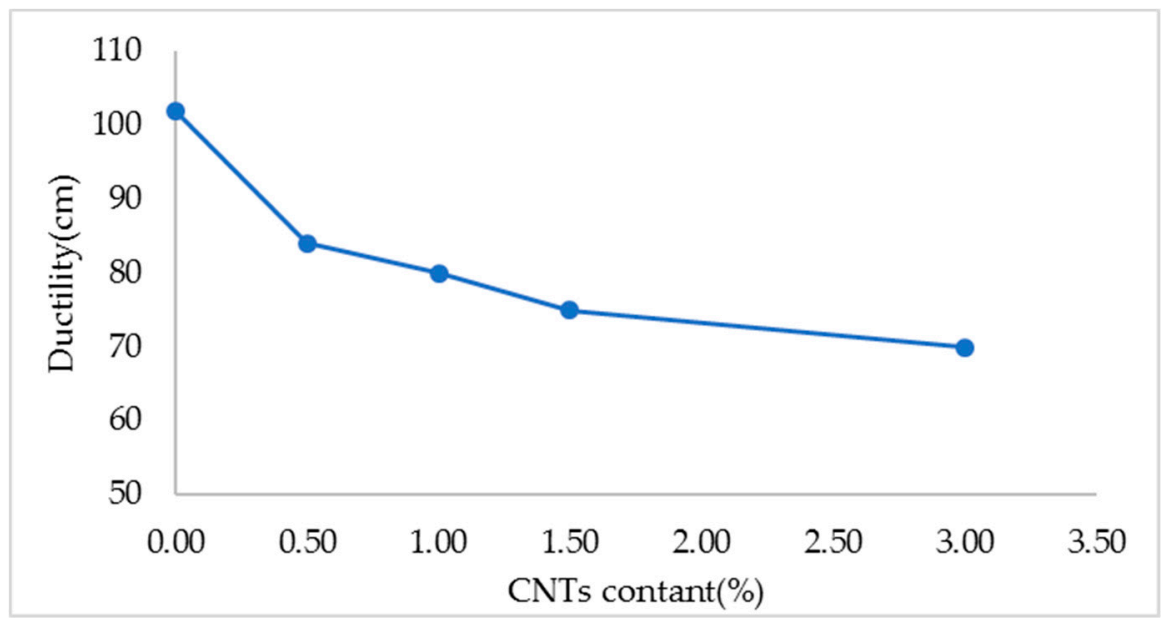

Figure 10. Ductility of bitumen with different contents of CNTs.

\subsection{Dynamic Shear Rheological Properties}

Dynamic shear rheometer test was performed to check the rheological properties of asphalt binder at intermediate to high temperatures for different frequencies. Figure 11 shows that an increase in failure temperature of the bitumen was observed when increasing percentages of MWCNTs were introduced. Failure temperature of the bitumen for unaged samples was determined as per superpave method. Temperature at which $\mathrm{G}^{*} / \operatorname{Sin} \delta$ becomes less than $1 \mathrm{kPa}$ is failure temperature for unaged asphalt binder [45]. The failure temperature of original bitumen was about $61{ }^{\circ} \mathrm{C}$, so the upper performance grade of original asphalt binder was $58^{\circ} \mathrm{C}$. By increasing the $\mathrm{CNT}$ dosage, the failure temperature of samples was also increased, which is an indication of the reduction in temperature susceptibility. At $0.5 \%$ dosage, high PG grade of bitumen was 64 , while the PG grades for $1 \%$ and $3 \%$ CNTs modified bitumens were 70 and 76 , respectively. It means that a $3 \%$ dosage of CNTs resulted in three grade bumps. The climate in most of Pakistan is hot and summer air temperature rises up to $50{ }^{\circ} \mathrm{C}$ and in winter it hardy drops below $0{ }^{\circ} \mathrm{C}$. PG 70 is recommended for most regions of the country [46]. This study aimed at achieving a PG 76 after a great bump in the required PG 70 to accommodate the overloading on the highways of the country.

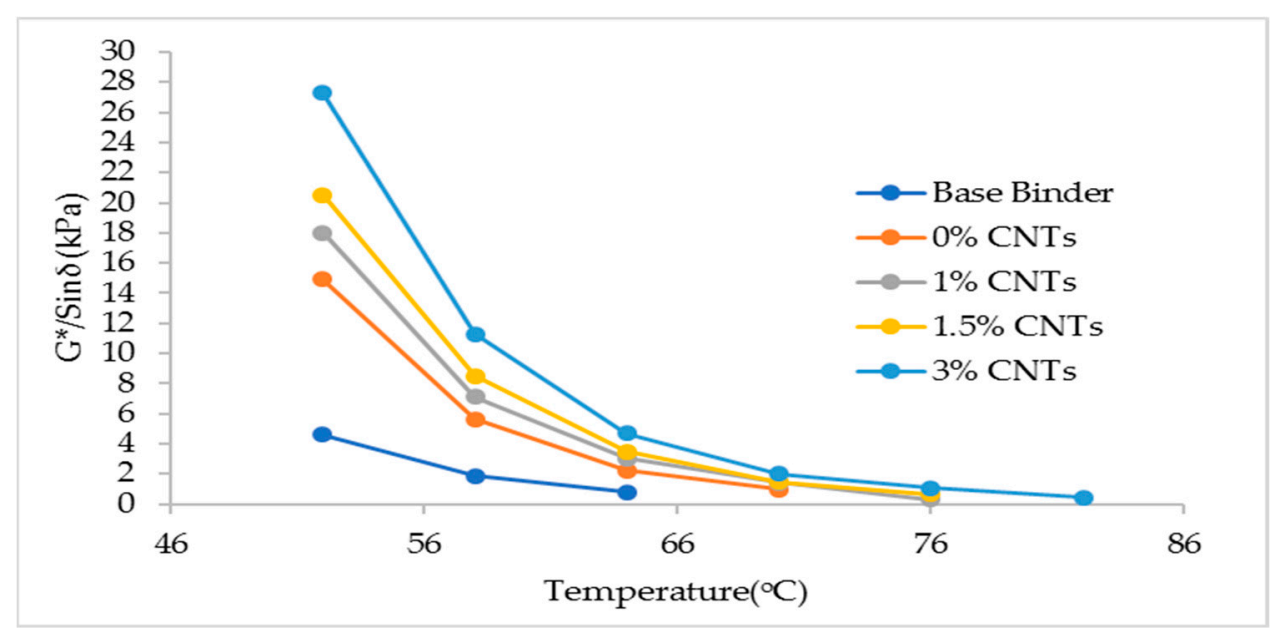

Figure 11. Rutting parameter $\left(\mathrm{G}^{*} / \operatorname{Sin} \delta\right)$ versus temperature for unaged asphalt binder at $10 \mathrm{rad} / \mathrm{s}$.

Figure 12 shows master curve of Complex Shear Modulus $\left(\mathrm{G}^{*}\right)$ at $58{ }^{\circ} \mathrm{C}$ for unmodified and CNT-modified bitumen. The $\mathrm{G}^{*}$ value increased from $3132 \mathrm{~Pa}$ to $14,264 \mathrm{~Pa}$ at $10 \mathrm{~Hz}$ frequency with the addition of $3 \%$ of CNTs. By increasing the content of MWCNTs in the original asphalt binder, the 
$G^{*}$ value increased, which is an indication of increase in bitumen stiffness and its resistance against permanent deformation at higher temperature. Bitumen is a viscoelastic material that shows viscous behavior at higher temperature and elastic behavior at low temperature. Phase angle is used to describe the bitumen elastic or viscous behavior. In Figure 13, it can be seen that, with the increase of CNTs in bitumen, phase angle of binder decreased, which is an indication of the increase in elastic behavior of bitumen [33]. The smaller is the phase angle, the higher is the elastic recovery when bitumen pavements are subjected to traffic at high temperatures. Thus, for MWCNT-modified bitumen, the chances of permanent deformation at higher temperatures are low.

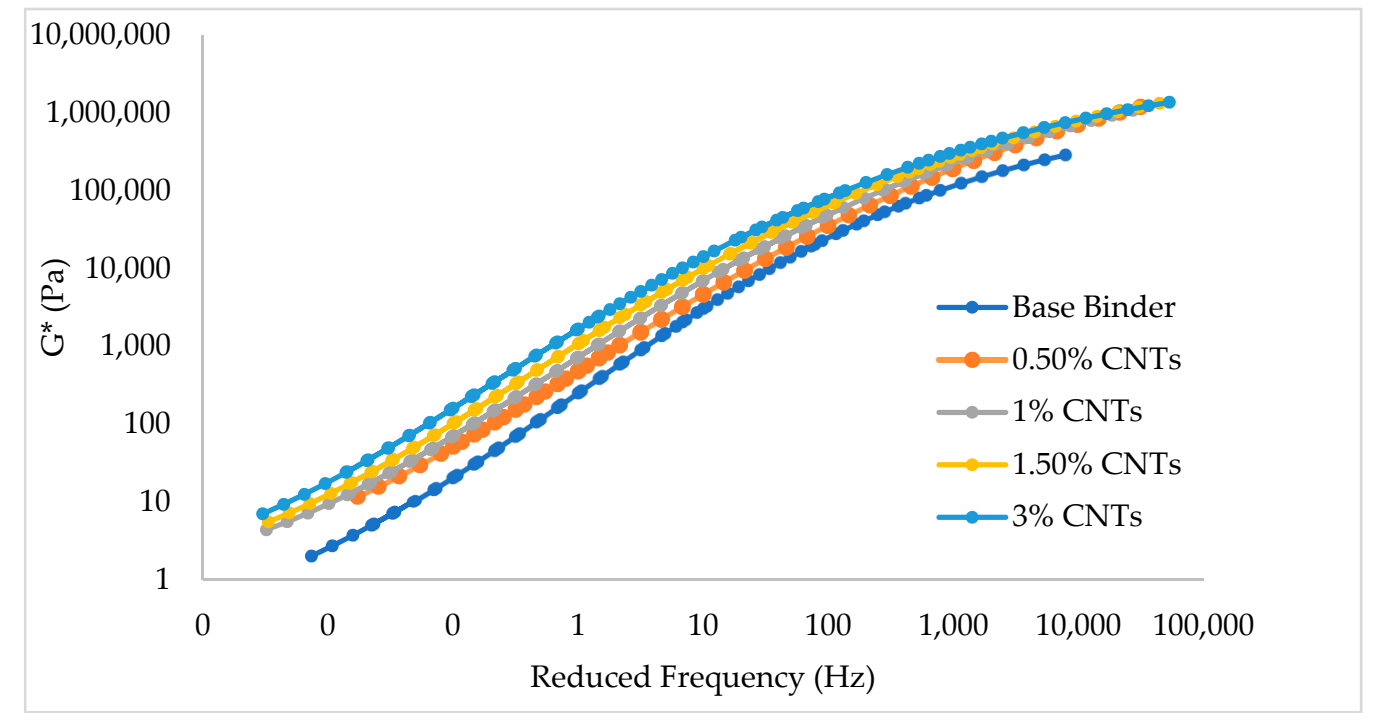

Figure 12. Master curve of $\mathrm{G}^{*}$ for $\mathrm{CNT}$-modified and unmodified bitumen at $58^{\circ} \mathrm{C}$.

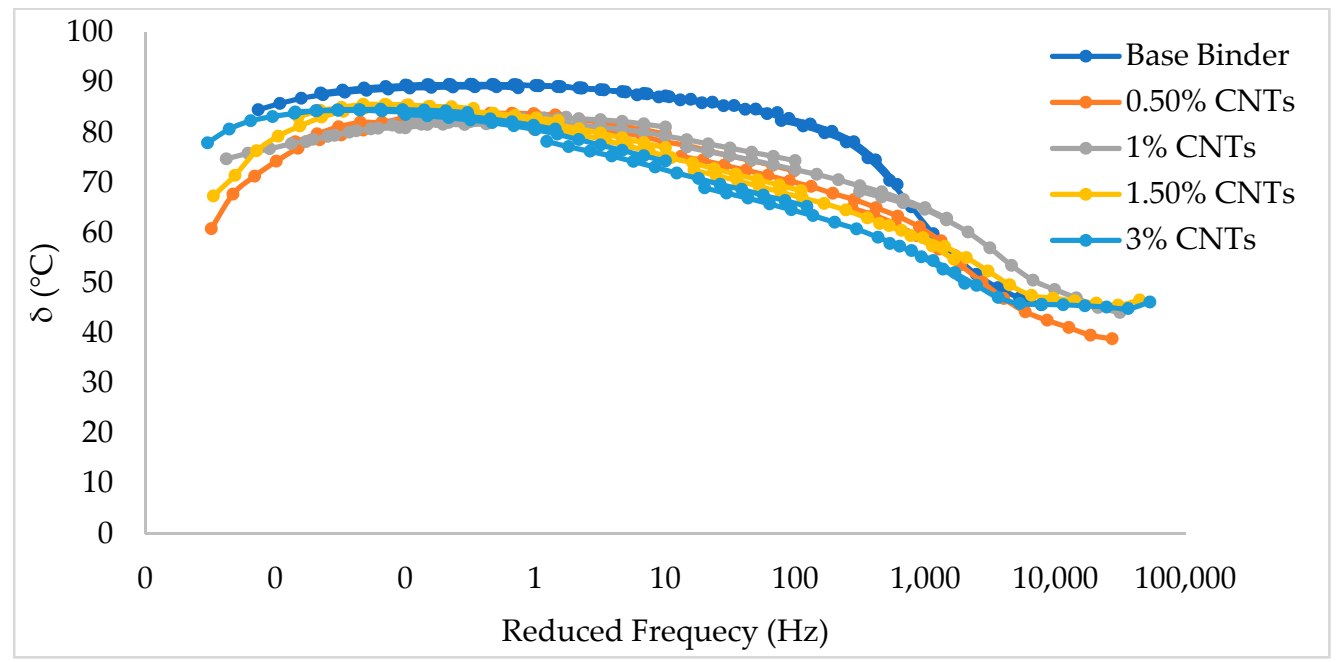

Figure 13. Master curve of $\delta$ for CNT-modified and unmodified bitumen at $58^{\circ} \mathrm{C}$.

One of the most important problems for asphaltic pavement is the deformation of the pavement in the wheel path due to heavy traffic at high temperature, which is called rutting. The parameter $\mathrm{G}^{*} / \mathrm{Sin} \delta$ is called rut factor and predicts the failure of binder at high temperature. Figure 14 shows that, with the modification of bitumen with MWCNTs, this parameter improved, which means the materials resistance against the rutting is enhanced at higher temperatures. The same effect was observed by Amin et al. (2016) [33]. 


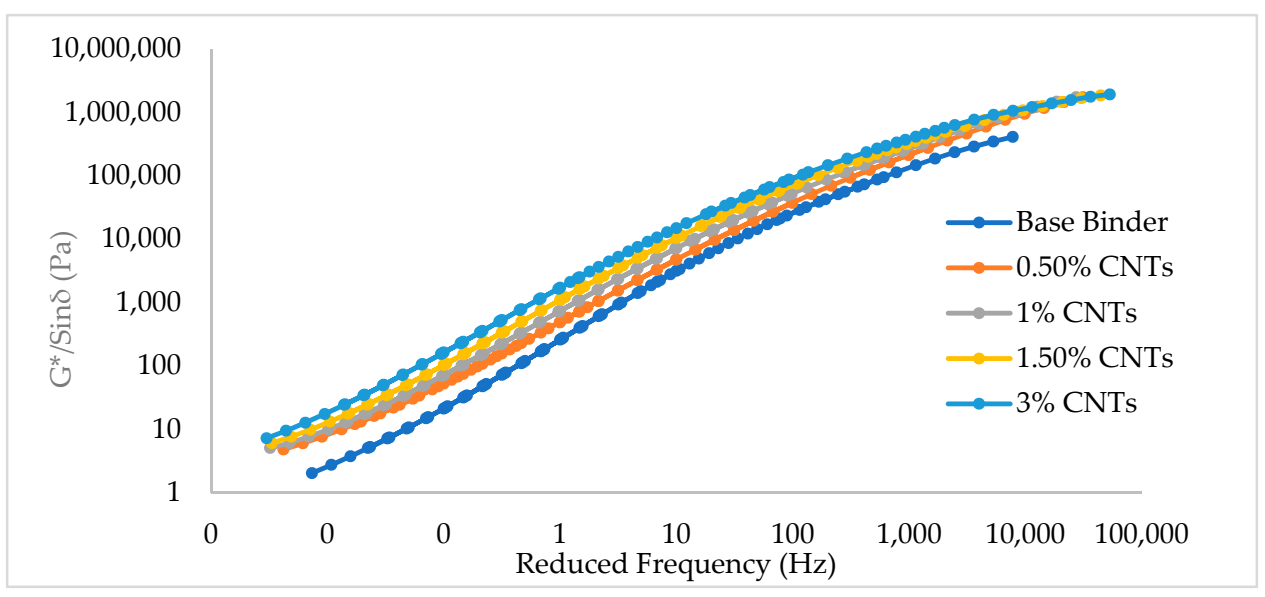

Figure 14. Master curve of $\mathrm{G}^{*} / \mathrm{Sin} \delta$ for $\mathrm{CNT}$-modified and unmodified bitumen at $58^{\circ} \mathrm{C}$.

Complex shear modulus $\left(\mathrm{G}^{*}\right)$ and phase angle $(\delta)$ obtained by frequency sweep test are represented in the form of black diagram in Figure 15. Black diagram is free of frequency and temperature. It allows all the data to be presented in a single graph. As shown in Figure 15, the viscoelastic properties of bitumen were very sensitive to CNTs content, as there was a significant change in the curves obtained for unmodified binder in comparison to the binder modified with different dosages of CNTs. It was observed that, with increase in temperature, phase angle of bitumen increased and $\mathrm{G}^{*}$ value decreased. After a threshold point in Figure 15, it was observed that, for the CNT-modified asphalt binder, phase angle at high temperature and low frequencies tend to decrease as compared to base binder which means the elastic behavior of bitumen increased at high temperature for these percentages. Thus, resistance against deformation increased with the addition of CNTs in bitumen [16].

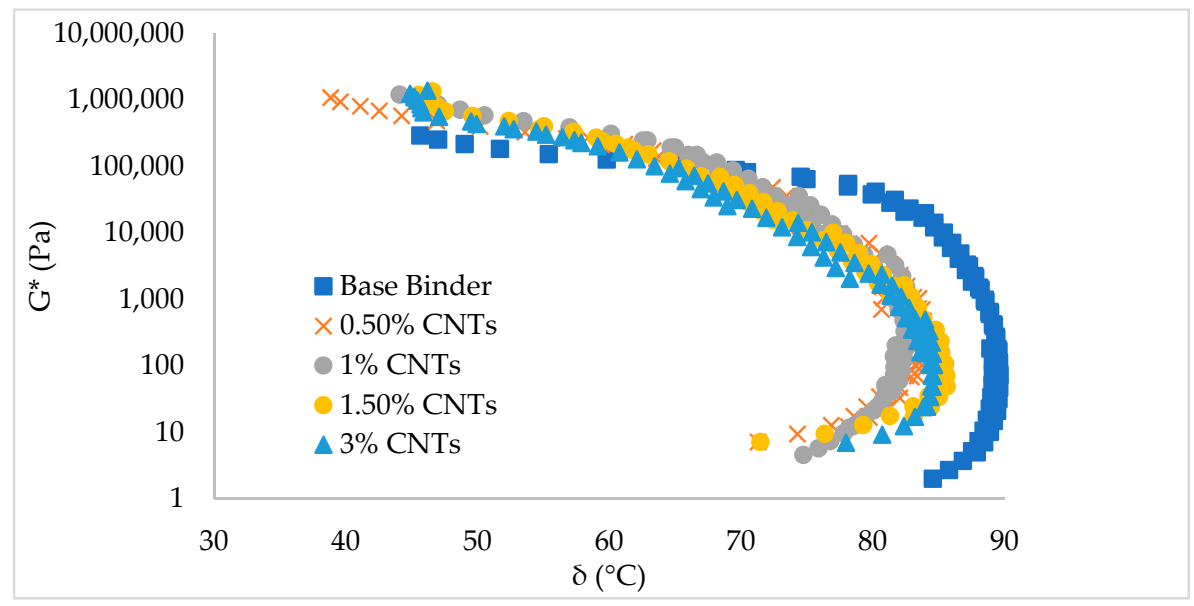

Figure 15. Black diagram for unmodified and CNT-modified binder.

\subsection{Bitumen-Aggregate Bond Strength Analysis}

The results of the bitumen bond strength test with aggregate after both dry and wet conditions are shown in Table 6 with failure pattern. In this table, the addition of CNTs improved the adhesion of bitumen with aggregate. Burst pressure obtained by PATTI was converted into pull off tensile strength using following relationship.

$$
\text { POTS }=\frac{\left(B P * A_{g}\right)-C}{A_{p s}}
$$

where $B P$ is burst pressure, $A_{g}$ is the contact area between gasket and reaction plate, $C$ is piston constant and $A_{p s}$ is area of pull off stub. For F4 type of stub, $A_{g}$ is $4.06 \mathrm{in}^{2}, C$ is 0.286 and $A_{g s}$ is $0.1963 \mathrm{in}^{2}$. 
Table 6. POTS (psi) of unmodified and CNT-modified binders and failure pattern.

\begin{tabular}{|c|c|c|c|c|c|c|c|c|c|c|}
\hline & \multicolumn{5}{|c|}{24 h Dry Conditions (psi) } & \multicolumn{5}{|c|}{24 h Wet Conditions (psi) } \\
\hline & $0 \%$ & $0.5 \%$ & $1 \%$ & $1.5 \%$ & $3 \%$ & $0 \%$ & $0.5 \%$ & $1 \%$ & $1.5 \%$ & $3 \%$ \\
\hline \multirow{2}{*}{1} & 1266.4 & 1493.9 & 1587.0 & 1868.3 & 1994.4 & 1119.5 & 1254.0 & 1361.5 & 1514.6 & 1555.9 \\
\hline & $(\mathrm{C})$ & (C) & (C) & (C/A) & (C) & (A) & $(\mathrm{A})$ & (A) & (A) & $(\mathrm{C} / \mathrm{A})$ \\
\hline \multirow{2}{*}{2} & 1206.4 & 1512.5 & 1570.4 & 1818.6 & 1907.5 & 1059.6 & 1287.1 & 1440.1 & 1496 & 1549.7 \\
\hline & $(\mathrm{C})$ & (C) & $(\mathrm{C})$ & $(\mathrm{C})$ & $(\mathrm{C})$ & (A) & $(\mathrm{A})$ & (A) & $(\mathrm{C} / \mathrm{A})$ & $(\mathrm{C} / \mathrm{A})$ \\
\hline \multirow{2}{*}{3} & 1270.5 & 1469.1 & 1560.1 & 1721.4 & 1797.9 & 1076.1 & 1295.3 & 1328.4 & 1613.9 & 1438.1 \\
\hline & $(\mathrm{C})$ & $(\mathrm{C})$ & $(\mathrm{C})$ & $(\mathrm{C})$ & $(\mathrm{C} / \mathrm{A})$ & $(\mathrm{A})$ & $(\mathrm{A})$ & (A) & $(\mathrm{C} / \mathrm{A})$ & $(\mathrm{C} / \mathrm{A})$ \\
\hline \multirow{2}{*}{4} & 1305.7 & 1485.6 & 1580.8 & 1642.8 & 1924.1 & 1080.2 & 1318.1 & 1527 & 1409 & 1630.4 \\
\hline & (C) & $(\mathrm{C})$ & $(\mathrm{C})$ & $(\mathrm{C})$ & $(\mathrm{C} / \mathrm{A})$ & $(\mathrm{A})$ & $(\mathrm{A})$ & $(\mathrm{A})$ & $(\mathrm{A})$ & $(\mathrm{A})$ \\
\hline \multirow{2}{*}{5} & 1258.1 & 1510.4 & 1607.7 & 1992.3 & 1961.3 & 1067.8 & 1299.5 & 1384.3 & 1518.7 & 1678.0 \\
\hline & (C) & (C) & (C) & $(\mathrm{C} / \mathrm{A})$ & $(\mathrm{C} / \mathrm{A})$ & (A) & (A) & (A) & (A) & (A) \\
\hline Avg & 1261.4 & 1494.3 & 1581.2 & 1808.7 & 1917.1 & 1080.7 & 1290.8 & 1408.3 & 1510.4 & 1570.4 \\
\hline
\end{tabular}

It can be seen from the results that POTS for CNT-modified asphalt binders were higher than for the unmodified asphalt binder in both dry and wet conditions. In dry conditions, most of the failure was cohesive failure, while adhesive failure was observed in most of the samples tested after wet conditioning due to the penetration of water at the interface between bitumen and aggregate, which weakened the bond and resulted in reduction of POTS [47]. CNT-modified bitumen showed less susceptibility to moisture as compared to unmodified bitumen due to the hydrophobic nature of CNTs [48]. In dry condition, addition of $0.5 \%$ of CNTs resulted in an increase of POTS by $19 \%$ as compared to base binder. As the bitumen content increased, POTS tended to increase. With $3 \%$ addition of CNTs, POTS increased by a value of $52 \%$, while, in wet mixing, $3 \%$ CNTs increased the POTS by $45 \%$.

\subsection{Moisture Susceptibility Analysis}

Rolling bottle test was used to check the moisture susceptibility of asphalt binder with aggregate. In Figure 16, the percentage loss of aggregate at different durations with unmodified and CNT-modified bitumen is represented. In Figure 17, it can be observed that, with the addition of CNTs in bitumen, the percentage loss of coating was decreased, which means the adhesion between aggregate and bitumen under moist conditions tended to increase in the presence of CNTs. This addition of $1 \%$ and $3 \%$ CNTs in bitumen improved the coating of binder by $20 \%$ and $40 \%$, respectively, at $72 \mathrm{~h}$. According to Liu et al. [49], stiff binder shows better resistance against moisture. This improvement in coating may be attributed to the presence of CNTs in asphalt binder, which made bitumen stiff, as well as to the hydrophobic nature of CNTs [37].

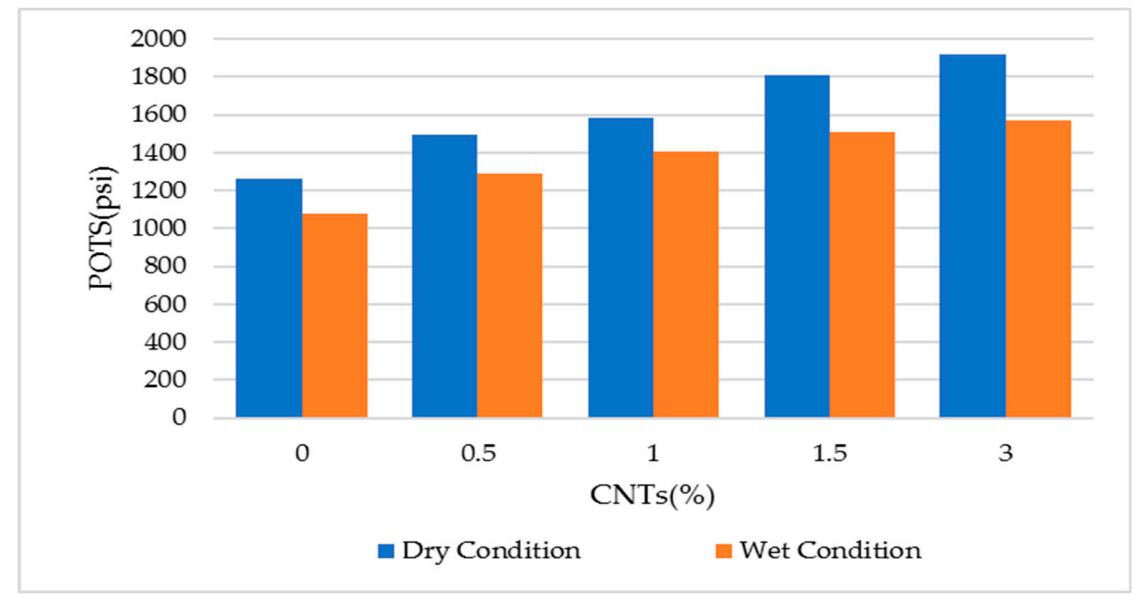

Figure 16. Comparison of POTS in $24 \mathrm{~h}$ dry and wet conditions. 


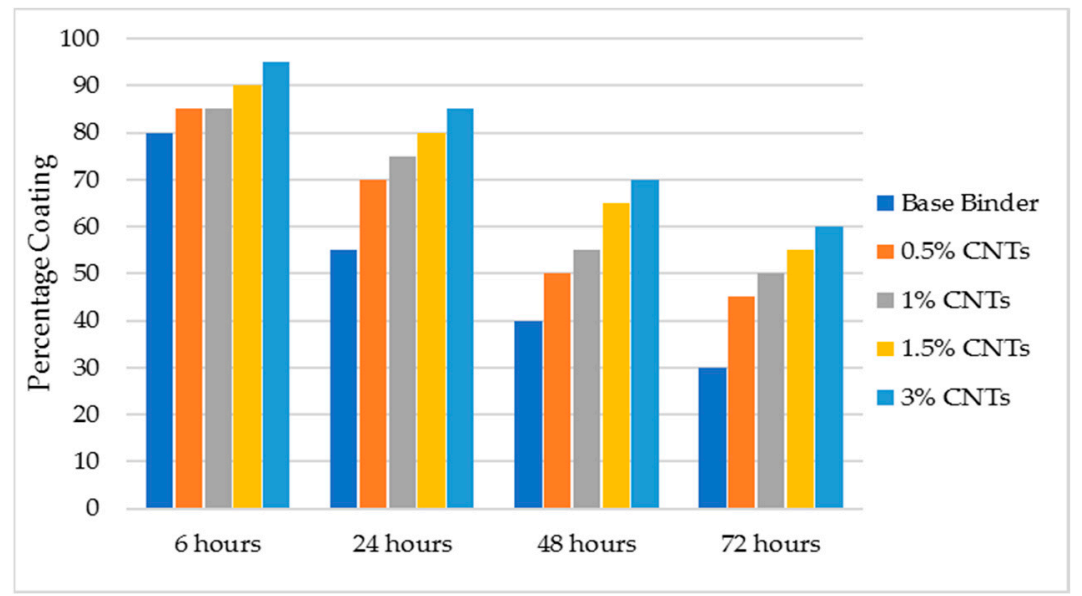

Figure 17. Loss of Coating at different durations with various CNTs percentages.

\subsection{Permanent Deformation Analysis}

Cooper wheel tracker test result for the rut depth of different dosages of CNTs is shown in Figure 18. It is clear from the results that, with the addition of CNTs, resistance against rutting increased. Rut depth value decreased with respect to base binder by up to $25 \%$ and $37 \%$ with the addition of $1 \%$ and $3 \%$ of CNTs, respectively, at $40{ }^{\circ} \mathrm{C}$. Rut depth decreased because the introduction of $\mathrm{CNTs}$ in binder increased its stiffness. Addition of CNTs improved the high temperature performance of asphalt mixtures by improving the elastic response of the bitumen. Moreover, addition of the CNTs to the binder due to the high specific surface can reinforce the bitumen particles and enhance the strength of bitumen particles. The above factor can increase the viscosity and adhesion of asphalt binder and decrease its sensitivity to the permanent deformation [37].

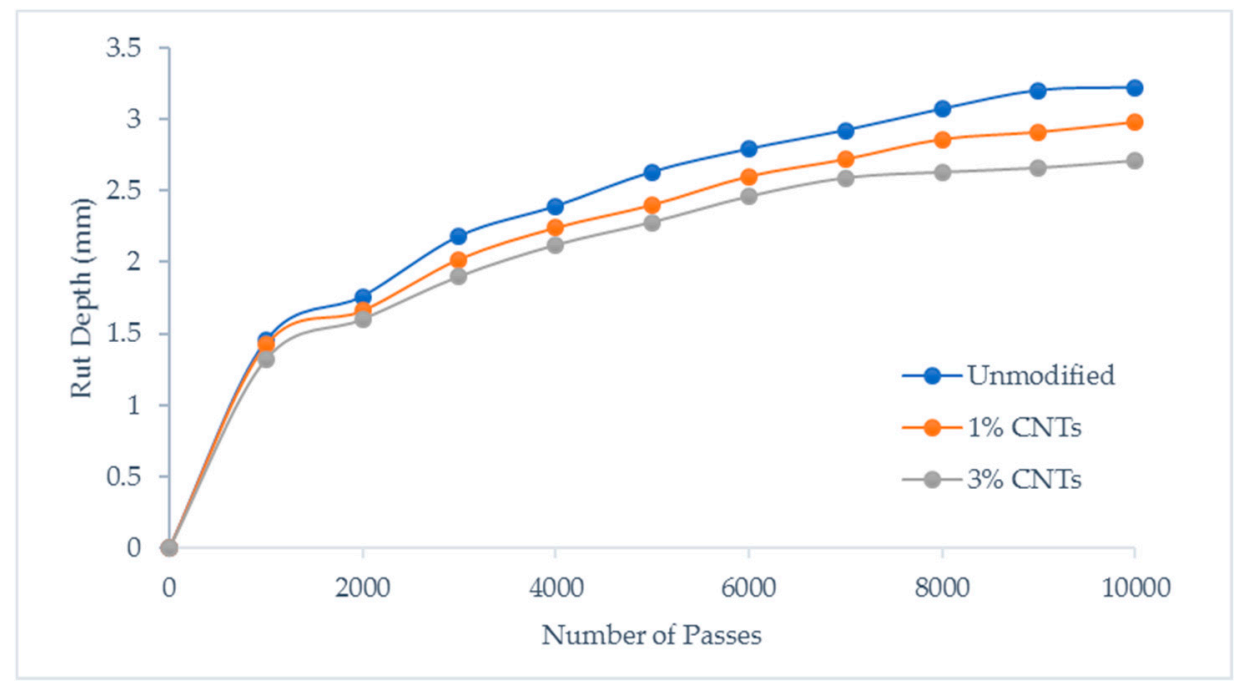

Figure 18. Rut depth for unmodified and CNT-modified bitumen mix at $40{ }^{\circ} \mathrm{C}$.

\section{Conclusions and Recommendations}

This study experimentally developed an understanding of the effect of adding carbon nanotubes in asphalt bitumen. Dynamic mechanical analysis and different performance tests were carried out. Different tests were performed on asphalt binder as well as asphalt mixtures. The following conclusions were drawn from the above research

- Wet mixing techniques better helps in achieving homogeneous dispersion of CNTs in bitumen as compared to dry mixing. 
- Sonication and magnetic stirring are necessary to improve the stability of CNTs in solvent.

- Introduction of CNTs in asphalt binder resulted in reduction in penetration value and ductility value, while it increased the softening point value of the bitumen, which means stiffness of the bitumen increased with the addition of CNTs.

- With the addition of CNTs, the PI value of bitumen increased, which means the bitumen temperature sensitivity decreased and thermal susceptibility also decreased.

- Complex shear modulus $\left(\mathrm{G}^{*}\right)$ value increased and phase angle of the bitumen tended to decrease with increase in CNTs, which means the stiffness and elastic behavior of bitumen improved with the addition of CNTs in asphalt binder. Rut factor value also improved, which indicates the increase in resistance against permanent deformation.

- High Performance Grade (PG) of the bitumen increased with an increase in the CNTs dosage. PG 70 is recommended for most of the regions of Pakistan. This study aimed for achieving a PG 76 after a great bump in the required PG 70 to accommodate for the overloading on the highways of the country. The required PG 76 was achieved with $3 \%$ addition of CNTs in bitumen. Asphalt samples modified with 3\% CNTs showed improved results for all parameters examined in this study. Hence, $3 \%$ CNTs dosage was selected as the optimum dosage.

- Bitumen bond strength value improved by adding CNTs in bitumen in both $24 \mathrm{~h}$ dry and $24 \mathrm{~h}$ moist conditions, while moisture susceptibility of bitumen decreased with addition of CNTs.

- From wheel tracker test results, it was concluded that the addition of $1 \%$ and $3 \%$ CNTs in bitumen reduced the rut depth by $25 \%$ and $37 \%$, respectively, when tested at $40{ }^{\circ} \mathrm{C}$. This is an indication of an increase in the resistance against permanent deformation at higher temperature for CNT-modified binder.

- Although wet mixing is a complicated process, it is preferred over the dry mixing technique because it ensures homogeneous dispersion of CNTs in the binder.

Author Contributions: Conceptualization, M.F.u.H. and N.A.; Data curation, M.F.u.H., Jamal, M.H., J.R. and S.B.A.Z.; Formal analysis, M.F.u.H., N.A. and Jamal; Investigation, M.F.u.H., Jamal, M.H. and J.R.; Methodology, M.F.u.H., N.A. and M.A.N.; Resources, M.F.u.H. and W.H.; Supervision, N.A.; Writing—original draft, M.F.u.H.; and Writing-review and editing, N.A., M.A.N., S.B.A.Z. and W.H.

Acknowledgments: The authors would like to acknowledge the support of the Civil Engineering department at The University of Lahore, Islamabad Campus in pursuit of this research work.

Conflicts of Interest: The authors declare no conflict of interest.

\section{References}

1. Kiel, J.; Smith, R.; Ubbels, B. The Impact of Transport Investments on Competitiveness. Transp. Res. Procedia 2014, 1, 77-88. [CrossRef]

2. Collins, J.H.; Bouldin, M.G.; Gelles, R.; Berker, A. Improved Performance of Paving Asphalts by Polymer Modification. J. Assoc. Asph. Paving Technol. 1991, 60, 43-49.

3. Sadeghpour, S.; Dabir, B.; Ehsan, A.; Moeini, A. Rheological properties and storage stability of bitumen/SBS/montmorillonite composites. Constr. Build. Mater. 2010, 24, 300-307. [CrossRef]

4. Alhamali, D.I.; Wu, J.; Liu, Q.; Hassan, N.A.; Yusoff, N.I.M.; Ali, S.I.A. Physical and Rheological Characteristics of Polymer Modified Bitumen with Nanosilica Particles. Arab. J. Sci. Eng. 2016, 41, 1521-1530. [CrossRef]

5. Golewski, G.L. Generalized fracture toughness and compressive strength of sustainable concrete including low calcium fly ash. Materials (Basel) 2017, 10, 1393. [CrossRef] [PubMed]

6. Sengoz, B.; Isikyakar, G. Evaluation of the properties and microstructure of SBS and EVA polymer modified bitumen. Constr. Build. Mater. 2008, 22, 1897-1905. [CrossRef]

7. Yildirim, Y. Polymer modified asphalt binders. Constr. Build. Mater. 2007, 21, 66-72. [CrossRef]

8. Behnood, A.; Modiri Gharehveran, M. Morphology, rheology and physical properties of polymer-modified asphalt binders. Eur. Polym. J. 2018. [CrossRef] 
9. Amin, I.; El-Badawy, S.M.; Breakah, T.; Ibrahim, M.H.Z. Laboratory evaluation of asphalt binder modified with carbon nanotubes for Egyptian climate. Constr. Build. Mater. 2016, 121, 361-372. [CrossRef]

10. Raki, L.; Beaudoin, J.; Alizadeh, R.; Makar, J.; Sato, T. Cement and concrete nanoscience and nanotechnology. Materials (Basel) 2010, 3, 918-942. [CrossRef]

11. Sanchez, F.; Sobolev, K. Nanotechnology in concrete-A review. Constr. Build. Mater. 2010, 24, $2060-2071$. [CrossRef]

12. Li, R.; Xiao, F.; Amirkhanian, S.; You, Z.; Huang, J. Developments of nano materials and technologies on asphalt materials-A review. Constr. Build. Mater. 2017, 143, 633-648. [CrossRef]

13. Shafabakhsh, G.H.; Ani, O.J. Experimental investigation of effect of Nano TiO2/SiO2 modified bitumen on the rutting and fatigue performance of asphalt mixtures containing steel slag aggregates. Constr. Build. Mater. 2015, 98, 692-702. [CrossRef]

14. Fang, C.; Yu, R.; Liu, S.; Li, Y. Nanomaterials Applied in Asphalt Modification : A Review. J. Mater. Sci. Technol. 2013, 29, 589-594. [CrossRef]

15. Li, R.; Pei, J.; Sun, C. Effect of nano-ZnO with modified surface on properties of bitumen. Constr. Build. Mater. 2015, 98, 656-661. [CrossRef]

16. Shu, B.; Wu, S.; Pang, L.; Javilla, B. The utilization of multiple-walled carbon nanotubes in polymer modified bitumen. Materials (Basel) 2017, 10, 416. [CrossRef] [PubMed]

17. El-Shafie, M.; Ibrahim, I.M.; Abd El Rahman, A.M.M. The addition effects of macro and nano clay on the performance of asphalt binder. Egypt. J. Pet. 2012, 21, 149-154. [CrossRef]

18. Amin, G.M.; Esmail, A. Application of nano silica to improve self-healing of asphalt mixes. J. Cent. South Univ. 2017, 24, 1019-1026. [CrossRef]

19. Amirkhanian, A.N.; Xiao, F.; Amirkhanian, S.N. Characterization of unaged asphalt binder modified with carbon nano particles. Int. J. Pavement Res. Technol. 2011, 4, 281-286. [CrossRef]

20. Santagata, E.; Baglieri, O.; Tsantilis, L.; Dalmazzo, D. Rheological Characterization of Bituminous Binders Modified with Carbon Nanotubes. Procedia-Soc. Behav. Sci. 2012, 53, 546-555. [CrossRef]

21. Treacy, M.M.J.; Ebbesen, T.W.; Gibson, J.M. Exceptionally high Young's modulus observed for individual carbon nanotubes. Nature 1996, 381, 678-680. [CrossRef]

22. de Heer, W.A. Nanotubes and the Pursuit of Applications. MRS Bull. 2004, 29, 281-285. [CrossRef]

23. Bai, J.B.; Allaoui, A. Effect of the length and the aggregate size of MWNTs on the improvement efficiency of the mechanical and electrical properties of nanocomposites - Experimental investigation. Compos. Part A Appl. Sci. Manuf. 2003, 34, 689-694. [CrossRef]

24. Gong, M.; Yang, J.; Yao, H.; Wang, M.; Niu, X.; Haddock, J.E. Investigating the performance, chemical, and microstructure properties of carbon nanotube-modified asphalt binder. Road Mater. Pavement Des. 2017, 0629, 1-24. [CrossRef]

25. Galooyak, S.S.; Palassi, M.; Farahani, H.Z.; Goli, A. Effect of carbon nanotube on the rheological properties of bitumen. Pet. Coal 2015, 57, 556-564.

26. Omar, H.A.; Yusoff, N.I.M.; Sajuri, Z.; Ceylan, H.; Jakarni, F.M.; Ismail, A. Determining the effects of aging on halloysite nano-tube modified binders through the pull-off test method. Constr. Build. Mater. 2016, 126, 245-252. [CrossRef]

27. Santagata, E.; Baglieri, O.; Tsantilis, L.; Chiappinelli, G. Fatigue properties of bituminous binders reinforced with carbon nanotubes. Int. J. Pavement Eng. 2015, 16, 80-90. [CrossRef]

28. Faramarzi, M.; Arabani, M.; Haghi, A.K.; Mottaghitalab, V. Carbon nanotubes-modified asphalt binder: Preparation and characterization. Int. J. Pavement Res. Technol. 2015, 8, 29-37. [CrossRef]

29. Hasan, Z.; Kamran, R.; Mohammad, F.; Ahmad, G.; Hosein, F. Evaluation of Different Conditions on The Mixing Bitumen and Carbon Nano-Tubes. Int. J. Civ. Environ. Eng. IJCEE-IJENS 2012, 12, 53-59.

30. Tufail, M.; Ahmad, N.; Mirza, S.M.; Mirza, N.M.; Khan, H.A. Natural radioactivity from the building materials used in Islamabad and Rawalpindi, Pakistan. Sci. Total Environ. 1992, 121, 283-291. [CrossRef]

31. Hussan, S.; Kamal, M.A.; Hafeez, I.; Farooq, D.; Ahmad, N.; Khanzada, S. Statistical evaluation of factors affecting the laboratory rutting susceptibility of asphalt mixtures. Int. J. Pavement Eng. 2017, 8436, 1-15. [CrossRef]

32. Ziari, H.; Hosein, F.; Goli, A. Using the Statistical Analysis of Carbon Nano-tubes Dispersion in Bitumen Employing Software MINITAB. Int. J. Transp. Eng. 2013, 1, 125-136. 
33. Amin, I.; El-Badawy, S.M.; Breakah, T.; Ibrahim, M.H.Z. Effect of Functionalization and Mixing Process on the Rheological Properties of Asphalt Modified with Carbon Nanotubes. Am. J. Civ. Eng. Archit. 2016, 4, 90-97. [CrossRef]

34. Collett, B.M. Scanning Electron Microscopy: A Review And Report Of Research In Wood Science. Wood Fiber Sci. 1967, 2, 113-132.

35. Ameri, M.; Vamegh, M.; Rooholamini, H.; Haddadi, F. Investigating Effects of Nano/SBR Polymer on Rutting Performance of Binder and Asphalt Mixture. Adv. Mater. Sci. Eng. 2018, 2018. [CrossRef]

36. Qasim, Z.I.; Qasim, Z.I. Effect of Filler Content on Properties of Asphaltic Mixtures for Marshall and Superpave Gyratory Compactor. Al-Nahrain J. Eng. Sci. 2017, 20, 183-193.

37. Chelovian, A.; Shafabakhsh, G. Laboratory evaluation of Nano Al2O3effect on dynamic performance of stone mastic asphalt. Int. J. Pavement Res. Technol. 2017, 10, 131-138. [CrossRef]

38. Hussain, M.H.M.; Ghaly, N.F.; Ibrahim, I.M. Modified Hot Mix Asphalt for Road Maintenance. World Appl. Sci. J. 2008, 5, 236-245.

39. Rafi, J.; Kamal, M.; Ahmad, N.; Hafeez, M.; Faizan ul Haq, M.; Aamara Asif, S.; Shabbir, F.; Bilal Ahmed Zaidi, S. Performance Evaluation of Carbon Black Nano-Particle Reinforced Asphalt Mixture. Appl. Sci. 2018, 8, 1114. [CrossRef]

40. Atif, R.; Inam, F. Reasons and remedies for the agglomeration of multilayered graphene and carbon nanotubes in polymers. Beilstein J. Nanotechnol. 2016, 7, 1174-1196. [CrossRef]

41. Faramarzi, M.; Arabani, M.; Haghi, A.K.; Motaghitalab, V. A Study on the Effects of CNT's on Hot Mix Asphalt Marshal-Parameters. In Proceedings of the 7thSASTech 2013, Bandar-Abbas, Iran, 7-8 March 2013; pp. 1-9.

42. Ehinola, O.A.; Falode, O.A.; Jonathan, G. Softening point and Penetration Index of bitumen from parts of Southwestern Nigeria. NAFTA 2012, 63, 319-323.

43. Al-Omari, A.A.; Khedaywi, T.S.; Khasawneh, M.A. Laboratory characterization of asphalt binders modified with waste vegetable oil using SuperPave specifications. Int. J. Pavement Res. Technol. 2018, 11, 68-76. [CrossRef]

44. Enieb, M.; Diab, A. Characteristics of asphalt binder and mixture containing nanosilica. Int. J. Pavement Res. Technol. 2017, 10, 148-157. [CrossRef]

45. Ali, S.I.A.; Ismail, A.; Karim, M.R.; Yusoff, N.I.M.; Al-Mansob, R.A.; Aburkaba, E. Performance evaluation of Al2O3 nanoparticle-modified asphalt binder. Road Mater. Pavement Des. 2017, 18, 1251-1268. [CrossRef]

46. Mirza, M.W.; Abbas, Z.; Rizvi, M.A. Temperature Zoning of Pakistan for Asphalt Mix Design. Pakistan J. Eng. Appl. Sci. 2011, 8, 49-60.

47. Moraes, R.; Velasquez, R.; Bahia, H. Measuring the Effect of Moisture on Asphalt-Aggregate Bond with the Bitumen Bond Strength Test. Transp. Res. Rec. J. Transp. Res. Board 2011, 2209, 70-81. [CrossRef]

48. Kyakuno, H.; Fukasawa, M.; Ichimura, R.; Matsuda, K.; Nakai, Y.; Miyata, Y.; Saito, T.; Maniwa, Y. Diameter-dependent hydrophobicity in carbon nanotubes. J. Chem. Phys. 2016, 145. [CrossRef]

49. Liu, Y.; Apeagyei, A.; Ahmad, N.; Grenfell, J.; Airey, G. Examination of moisture sensitivity of aggregate-bitumen bonding strength using loose asphalt mixture and physico-chemical surface energy property tests. Int. J. Pavement Eng. 2014, 15, 657-670. [CrossRef]

(C) 2018 by the authors. Licensee MDPI, Basel, Switzerland. This article is an open access article distributed under the terms and conditions of the Creative Commons Attribution (CC BY) license (http://creativecommons.org/licenses/by/4.0/). 